\title{
Das pessoas às instituições: o Janus no ideário em educação física e ciências do desporto dos países lusófonos
}

Go Tani

https://doi.org/10.5628/rpcd.10.01.207
Escola de Educação Física e Esporte

Universidade de São Paulo

São Paulo

Brasil

\section{RESUMO}

Existe um reconhecimento de que o chamado Movimento Lusófono da Educação Física e Desporto foi muito bem sucedido, ao longo dos seus 21 anos de existência, na realização de sua meta que é encurtar distâncias, aproximar pessoas e instituições que têm como objetivo comum o estudo da Educação Física e do Desporto, e que esse sucesso baseou-se fundamentalmente em ações de pessoas e muito pouco de instituições. O presente ensaio teve como objetivo colocar em discussão as metas desse Movimento visando ao seu desenvolvimento sustentável no futuro e propõe que para tanto é preciso, sem abrir mão do envolvimento e dedicação pessoais, absolutamente fundamentais, passar a ações mais concretas de natureza institucional, e discute algumas preocupações nessa mudança de estratégia tendo como pano de fundo a ideia de hólon proposta por Koestler (1967).

Palavras-chave: educação física, desporto, hólon

\begin{abstract}
From persons to institutions: the Janus in the system of academic ideas of physical education and sport sciences in the Portuguese language speaking countries
\end{abstract}

There is a recognition that the so-called Physical Education and Sport Movement of the Portuguese Speaking Countries was very successful, along its 21 years of existence, in the achievement of its goal which is shortening distances, and approaching persons and institutions that have as a common preoccupation the study of Physical Education and Sport. It is also recognized that this success was basically dependent on actions of people rather than institutions. The objective of the present essay was to put in discussion the goals of this Movement aiming at its sustainable development in the future. It proposes that to achieve that end the Movement needs more concrete institutional actions, without renouncing the absolutely fundamental involvement and dedication of people, and discuss some concerns related to change in that strategy having as a background the idea of holon proposed by Koestler (1967).

Key-words: physical education, sport, holon 


\section{PALAVRAS INICIAIS}

O presente ensaio baseia-se na conferência de encerramento que foi proferida no XIII Congresso de Educação Física e Ciências do Desporto dos Países de Língua Portuguesa, realizado em Maputo Moçambique, em 2010.

É amplamente reconhecido que esse evento é a face mais visível de um grande Movimento que congrega docentes e pesquisadores das áreas de Educação Física e Desporto dos países lusófonos. Trata-se de uma coletividade que não se caracteriza como uma associação ou sociedade científica no seu sentido clássico, ou seja, uma entidade rigorosamente organizada e estruturada, com estatuto, regulamentos e normas, mas sim um Movimento dinâmico e adaptável em que a par de aspectos acadêmico-científicos, as relações humanas entre seus membros são valorizadas e cultivadas com muito carinho.

Essa natureza menos "formatada" desse Movimento traz, sabidamente, vantagens e desvantagens. E podese afirmar que o seu grande desafio reside exatamente nesse seu traço mais marcante: como conciliar a sua informalidade peculiar e saudável com as metas precípuas de toda e qualquer organização acadêmicocientífica, que exigem cada vez mais estruturas bem organizadas para serem efetivamente logradas?

Como todo movimento dessa natureza, esse também é propositado, direcionado a uma meta. Quais seriam as metas desse Movimento? Seriam as mesmas de 21 anos atrás, quando foi criado por iniciativa de dois visionários - Professores Jorge Olímpio Bento e Alfredo Gomes de Faria Júnior? Seriam as mesmas de treze anos atrás, quando da realização do primeiro congresso de Maputo? Seriam as metas desse Movimento mais restritas à realização de congressos bienais? Seria possível e teria sentido estabelecer metas acadêmico-científicas apenas internas, circunscritas a países lusófonos, num mudo cada vez mais globalizado?

Mais especificamente, seriam as metas desse Movimento vinculadas ao ciclo completo do conhecimento, ou seja, a sua produção, sistematização, disseminação e aplicação, ou a algumas etapas desse processo em particular? Seriam as metas relacionadas à investigação pura para saciar a curiosidade acadêmica, aquelas que deveriam ser abraçadas com maior entusiasmo, ou as direcionadas à intervenção visando à solução de problemas imediatos da sociedade?

Este congresso, ao estabelecer como tema central do evento a identidade acadêmica e profissional do Desporto, deu uma importante contribuição para a discussão dessa temática. Mas é preciso dar continuidade e avançar. Entendo que é chegado o momento de pensar de forma serena, mas focada, nessas questões de fundo. O Movimento pede a definição de uma posição mais clara que ilumine o caminho a ser percorrido. Oportuno lembrar que é a definição de metas que permite a escolha de estratégias mais adequadas para a sua realização e não o contrário. Nesse contexto, as relações humanas se estabeleceriam em torno das ações para alcançar as metas e se fortaleceriam à medida de suas concretizações. O objetivo deste ensaio é refletir sobre essas questões - metas e estratégias - evidentemente não com o intuito de definir uma direção a ser seguida pelo Movimento, mas com a intenção de estimular o esforço coletivo no sentido de busca de uma melhor definição, talvez nos próximos congressos. Em outras palavras, contribuir para a construção de um novo ideário, um grande desafio, para o qual conto com a vossa compreensão, paciência e boa vontade.

\section{DAS PESSOAS ÀS INSTITUIÇÕES}

O primeiro congresso de Educação Física e Ciências do Desporto dos Países de Língua Portuguesa foi realizado em 1989 na cidade do Rio de Janeiro, tendo como meta principal encurtar distâncias, aproximar pessoas e instituições que têm como preocupação central o estudo da Educação Física e do Desporto, dando materialidade à vontade de cooperação mais estreita para projetar e afirmar uma comunidade científica no espaço da língua portuguesa (1).

Nesses 21 anos que se passaram muito foi feito para o alcance dessa meta inicialmente traçada no primeiro evento. Paremos para um pequeno balanço das ações empreendidas. Só de congressos foram mais doze edições em quatro países. Diz-se, frequentemente, que realizar o primeiro congresso não é tão difícil, mas dar continuidade com regularidade é seguramente um enorme desafio. Além dos congressos, várias ações foram desenvolvidas por esse Movimento, de forma que se fizermos um levantamento, dos trabalhos apresentados em todos esses congressos, das parcerias interinstitucionais estabe- 
lecidas no oferecimento de programas de Pós-graduação, dos programas de mobilidade docente e discente implementados tanto na Graduação como na Pós-graduação, da mobilidade docente para participação em bancas examinadoras de concurso, da publicação de artigos em periódicos de países irmãos, da publicação compartilhada de livros e da co-orientação de teses e dissertações entre membros desta comunidade, dentre tantas outras atividades acadêmicas relevantes, ficará claramente evidenciado que muito caminhamos nesse período para encurtar distâncias e aproximar pessoas e instituições.

Podemos concluir que o Movimento não se restringe à realização de congressos bienais e motivos não faltam para celebrar essas conquistas em altos brados: o Movimento é um sucesso. Mas, isto posto, alguém poderia imediatamente indagar: por que então mudar? Para que mudar um ideário que se revelou produtivo?

Posso estar enganado, mas encontro uma resposta a essas dúvidas e indagações: apesar do sucesso, as ações realizadas e as conquistas logradas por esse Movimento foram fundamentalmente baseadas em pessoas - com suas visões, seus ideais, seus sonhos, suas utopias, suas dedicações, seus compromissos, suas paixões - e muito pouco em instituições. Não há dúvida de que o modelo adotado até o presente foi bem sucedido, mas pensando o futuro entendo que chegou a hora de, sem abrir mão de todo esse envolvimento e dedicação pessoais, absolutamente fundamentais, passar a ações mais concretas de natureza institucional.

O cenário político, econômico, social, cultural, educacional e científico têm mudado muito nesses tempos, cada vez com maior intensidade e rapidez, surpreendendo-nos a todo o momento. Só para citar uma delas, de profunda implicação para todos nós: a universidade perdeu a hegemonia do conhecimento e está em profunda crise(13). O Movimento necessita estar atento a essas mudanças e mostrar seu dinamismo para dar respostas concretas à sociedade, e isto requer ações articuladas entre instituições.

Ademais, sabemos que quem faz a instituição são as pessoas, mas nem todas as pessoas compartilham de um mesmo ideário institucional. E cada pessoa tem o seu "tempo de validade" institucional. Parece-nos que, nesses anos todos, por feliz coincidência, as pessoas em postos de liderança nas institucionais partícipes compartilhavam do mesmo ideal no tocante a esse Movimento, mas nada garante a sua continuidade enquanto não houver compromissos institucionais estruturados e assumidos. As relações humanas solidárias, fraternas, de profunda amizade, construídas entre os seus membros ao logo desses 21 anos são um verdadeiro patrimônio desse Movimento que devem ser preservadas. As ações institucionais poderão fortalecê-las e ampliá-las ainda mais, mas isso depende das metas que se projetarem para o seu futuro.

A mudança que aqui se propõe, isto é, de ações mais centradas em pessoas para aquelas com maior envolvimento das instituições, pode parecer apenas de natureza estratégica. No entanto, reconhecendo o caráter indissociável entre metas e estratégias, entendo que essa mudança constitui um momento privilegiado para rediscutir as metas adequando-as às transformações sociais que ocorreram nesses 21 anos de vida do Movimento e às necessidades e desafios acadêmico-científicos do futuro.

\section{DO JANUS}

O título desta apresentação pode ter provocado estranhamento em algumas pessoas. Por que Janus? Qual o seu significado e que contribuições traria para a reflexão pretendida? O motivo é que desafios como esse que abracei reclamam um pano de fundo conceitual para uma análise serena e especialmente prudente. Perguntei-me: quais seriam as ferramentas conceituais para refletir sobre uma questão tão complexa como é a meta de uma organização acadêmicocientífica nos dias atuais? Onde buscar inspiração para não cair numa reflexão assente em dicotomias e dualidades que já se sabe inoperantes para lidar com problemas complexos?

Nas minhas indagações sobre as metas desse Movimento Lusófono da Educação Física e Desporto a conjunção "ou" esteve teimosamente presente. Existiria um construto, um quadro de referência que nos possibilitasse olhar para a árvore e a floresta ao mesmo tempo? Algo que permitisse conciliar polaridades que o pensamento dicotômico criou em nossas mentes, sem cair em discursos românticos esvaziados de praticidade, desconectados da realidade ou descompromissados com conseqüências práticas? 
Enfim, algo que permita substituir a conjunção "ou" por "e" em inúmeros pares dicotômicos que abundam em nossa mente: todo ou parte, ordem ou desordem, regularidade ou irregularidade, informação ou incerteza, consistência ou flexibilidade, regularidade ou aleatoriedade, precisão ou erro, interno ou externo, nacional ou internacional, investigação ou intervenção, entre tantos outros que costumeiramente lançamos mão em nossas reflexões e análises? Arthur Koestler, além de inúmeras obras literárias interessantes, deixou como legado um livro com profundas implicações para o pensamento científico e reflexão epistemológica: "O fantasma da máquina"(6). Trata-se de uma obra que deixou marcas profundas no desenvolvimento inicial do chamado pensamento sistêmico, ou mais amplamente, paradigma sistêmico. Ouso conjeturar que, juntamente com o livro "Teoria geral de sistemas" escrito por Ludwig von Bertalanffy(2) e "Cibernética" por Norbert Wiener(15), esse livro forma o alicerce das principais proposições do pensamento sistêmico apresentadas nas fases iniciais do seu desenvolvimento. Como é bem conhecido, o paradigma sistêmico teve desdobramentos posteriores com base em outras importantes contribuições teóricas como a complexidade $(7,14)$, a sinergética ${ }^{(4)}$, o $\operatorname{caos}^{(3,8)}$, a auto-organização( $(5,16)$, dentre outras. Koestler(6) afirma que qualquer forma de organização, individual ou social, é ordenada hierarquicamente, e que uma importante característica universal da hierarquia é a relatividade, e decerto a ambigüidade, entre os termos parte e todo. Uma parte significa algo fragmentário e incompleto e o todo algo completo em si mesmo. Além disso, Koestler(6) enfatiza que partes e todos em sentido absoluto não existem em lugar nenhum, no domínio dos organismos vivos e das organizações sociais. O que existem, na realidade, são estruturas intermediárias em diferentes níveis e numa ordem ascendente de complexidade. Essas estruturas intermediárias revelam, concomitantemente, algumas das características atribuídas aos todos e às partes, isto é, num certo sentido, são parte e todo ao mesmo tempo, dependendo da forma como as olhamos. Elas têm, como o deus romano Janus, duas faces que olham para direções opostas: uma voltada para os níveis subordinados que é a de um todo completo em si mesmo, e a outra voltada para cima, a de uma parte dependente.
Ao não encontrar uma palavra adequada para expressar essas estruturas intermediárias com tais características, Koestler(6) preferiu cunhar um novo termo para designar esses nós da organização hierárquica que funcionam parcialmente como todos e partes: hólon. Uma espécie de elo entre a concepção atomista e holista. Os hólons são governados por conjuntos fixos de regras que determinam as suas propriedades invariáveis, sua configuração estrutural, seu padrão funcional, e apresentam estratégias flexíveis para responder a contingências que caracterizam a sua propriedade variável. Cada hólon tem a tendência dupla de preservar e afirmar a sua individualidade como um todo autônomo - a tendência auto-afirmativa - e de funcionar como parte integrada de um todo maior - a tendência integrativa.

No comportamento humano a tendência auto-afirmativa se manifesta muitas vezes em forma de padrões fixos de ação e rotinas estereotipadas de pensamento, e a tendência integrativa reflete padrões flexíveis de ação e pensamentos criativos que iniciam novas formas de comportamento. Em condições normais essas duas tendências se contrabalançam e mantém um equilíbrio dinâmico. Em condições de tensão, rompe-se o equilíbrio dando origem a comportamentos desordenados.

Assim, o termo hólon pode ser aplicado a todo e qualquer sistema biológico ou social que manifeste coerência e estabilidade, ou seja, hierarquicamente ordenado. O Movimento Lusófono da Educação Física e Desporto pode ser visto como um hólon organizacional; uma faculdade de Educação Física e Desporto como um hólon institucional; as áreas de conhecimento da Educação Física e Desporto como hólons acadêmicos; os pesquisadores da Educação Física e Desporto como hólons intelectuais.

\section{O JANUS E AS AÇÕES INTERINSTITUCIONAIS}

Pensando o futuro do Movimento com essas proposições de Koestler(6), quais seriam as possibilidades mais visíveis para se intensificar as ações interinstitucionais holonômicas no seu interior? Várias podem ser pensadas.

No plano da investigação, explorando a tendência integrativa do hólon, o desenvolvimento de projetos temáticos entre instituições e laboratórios parece-nos de fundamental relevância. Certamente, a mobilidade 
de docentes e pesquisadores é importante para dar impulso à investigação, mas as relações acadêmicas nesse âmbito só se concretizam de fato quando se chega ao nível do desenvolvimento de projetos compartilhados de pesquisa, seja entre instituições, laboratórios ou grupos de pesquisa constituídos. O estudo longitudinal de crescimento e desenvolvimento motor em execução na cidade de Muzambinho Minas Gerais, Brasil, evolvendo a Universidade de São Paulo, a Universidade do Porto, a Universidade Pedagógica de Moçambique e a Escola Superior de Educação Física de Muzambinho pode ser visto como uma iniciativa concreta nessa direção.

No domínio do ensino de Graduação, para além da mobilidade estudantil, parcerias interinstitucionais para implantação da co-tutela e obtenção de duplo diploma constituem interessantes desafios a serem atacados. Respeitadas as peculiaridades institucionais e circunstâncias particulares de natureza local, regional ou nacional, o compartilhar entre as instituições lusófonas dos grandes desafios da formação universitária nos dias atuais, das reflexões institucionais amadurecidas, dos conhecimentos acumulados, das experiências inovadoras bem ou mal sucedidas no âmbito da formação profissional parece ser de indiscutível relevância coletiva. A criação de um fórum de discussões permanentes mediante o uso da tecnologia de informação seria de muita utilidade. $\mathrm{O}$ protocolo de Bologna e os desdobramentos da sua aplicação em Portugal é um bom exemplo de tema para discussão. A criação do bacharelado no Brasil, diferenciado da licenciatura, é outro tema que julgo interessante de ser abordado, sem querer provocar arrepios ou acordar fantasmas adormecidos em certos segmentos ideológicos da academia brasileira. No âmbito do ensino de Pós-graduação, a mobilidade docente já ocorre de forma regular e sistemática entre algumas instituições, mas no geral é ainda uma prática tímida na comunidade lusófona. Poderia ser significativamente intensificada mediante protocolos de cooperação acadêmica e convênios interinstitucionais. Como Pós-graduação é fundamentalmente pesquisa, entendo que é no desenvolvimento de projetos compartilhados de investigação entre pesquisadores, que reside o segredo de um salto qualitativo nessa área. Envolver pós-graduandos nesses empreendimentos interinstitucionais de investiga- ção, por exemplo, por meio de doutorados sanduíche, é uma maneira eficaz de formar recursos humanos qualificados para a docência no ensino superior e para o desenvolvimento de ciência e tecnologia. Decerto, esforços envolvendo uma ação integrada de instituições terão mais chances de obter recursos financeiros para viabilizar esses projetos junto aos órgãos de fomento nacionais e internacionais. É preciso criar demandas qualificadas.

No universo das atividades de cultura e extensão, a riqueza da cultura de movimento dos países lusófonos - especialmente jogo e dança - tanto em especificidade, quantidade como diversidade constitui um tesouro antropológico ainda inexplorado na nossa área, tanto em relação a sua investigação quanto disseminação. A exploração dessa cultura, quando presente, se sustenta em ações individuais e isoladas de docentes e pesquisadores, de forma que a sua dinamização necessitaria de ações articuladas entre instituições, procurando parceiros e financiadores de projetos nas suas respectivas áreas. Existe uma enorme potencialidade de se integrar as atividades de investigação, ensino e extensão relativas a essa cultura, mas a realização de todas essas ações requer envolvimento institucional consistente e duradouro. Em suma, o desenvolvimento sustentável do Movimento Lusófono da Educação Física e Desporto, incluindo a realização de seus congressos bienais, parece não poder mais depender apenas de iniciativas e esforços pessoais. Reclama também por ações institucionais planejadas estrategicamente. Reconhece-se que cada instituição tem problemas e desafios próprios que requerem a prática enfática da sua tendência auto-afirmativa, mas exercitar a outra face do Janus parece ser imprescindível quando se pensa no futuro dessa comunidade. E para tornar possível a articulação de ações pessoais e institucionais, algumas preocupações adicionais merecem destaque.

\section{OS PESQUISADORES LUSÓFONOS COMO HÓLONS}

Considerando os pesquisadores lusófonos da Educação Física e Desporto como hólons intelectuais, observa-se a sua tendência auto-afirmativa refletir-se de forma cada vez mais forte na preocupação e valorização das publicações em periódicos internacionais de impacto, independentemente da pertinência dessa produção à especificidade da sua 
área de conhecimento. A se continuar nessa tendência, corre-se o risco de tornar ainda mais indefinido o que já se encontra suficientemente ambíguo - a identidade acadêmica da Educação Física e do Desporto. Como pesquisadores vinculados a essas áreas é fundamental fazer com que a tendência integrativa se manifeste com mais vigor no sentido de utilizar a capacidade intelectual e criatividade para a produção de conhecimentos devidamente identificados com as suas especificidades. Muitas vezes, subjaz a essa forte manifestação da tendência auto-afirmativa o narcisismo intelectual de busca do status acadêmico pelo status.

Obviamente, não há nenhuma objeção a se fazer em relação à busca de publicações em periódicos internacionais de alta reputação. Ela será sempre bem vinda e deve ser fortemente encorajada. Mas todos sabem que ainda prevalece na ciência uma visão tendenciosa de considerar a pesquisa básica, especialmente em níveis mais microscópicos de análise, como mais científica e mais nobre do ponto de vista intelectual. E essa visão está presente na política editorial de muitos periódicos e acaba refletindo na avaliação dos artigos para efeito de publicação.

Infelizmente, a tendência auto-afirmativa dos pesquisadores da nossa área tende a se alinhar com esse modo de ver a ciência, até mesmo pela pressão existente na academia no que se refere à produtividade científica, de forma que a busca do conhecimento pelo conhecimento os leva muitas vezes a negligenciar a necessária preocupação acerca da pertinência das suas publicações à especificidade da área de conhecimento em que atuam.

O pesquisador é ao mesmo tempo causa e efeito de essa tendência auto-afirmativa prevalecer no interior da área. Tudo indica que a meta da Educação Física e Desporto nos países lusófonos, no âmbito da produção de conhecimentos, está fortemente orientada à obtenção do status e respeitabilidade acadêmicos. Isso tem implicado em dar pouca ênfase às pesquisas aplicadas comprometidas com solução de problemas encontrados na prática profissional. De fato, repetem-se no nosso meio as mesmas consequências negativas do "movimento disciplinar" ocorrido na década de 1960 nos EUA que foi uma ênfase quase que exclusiva à pesquisa acadêmico-científica de natureza básica, resultando num abandono de estu- dos de temas profissionalizantes e aplicados que abordassem problemas relevantes encontrados no âmbito da intervenção( $(9,10)$. A organização desse congresso procurou dar um equilíbrio a esses dois tipos de investigação na programação, mas obviamente não pode deixar de refletir, de alguma forma, essa tendência fortemente presente nas nossas áreas.

\section{AS ÁREAS COMO HÓLONS}

Mas, qual seria afinal a especificidade das áreas de Educação Física e Desporto? Trata-se de um tema ainda cercado de controvérsias. Parece-nos que existem ao menos dois problemas centrais de matriz epistemológica a serem resolvidos: o primeiro referese à caracterização dessas áreas como acadêmicas e/ou profissionalizantes, como já comentado; o segundo, se essas áreas pertencem ao domínio das ciências biológicas e/ou humanas e sociais. Como profissões, a Educação Física e o Desporto fazem parte daquelas denominadas de academicamente orientadas, ou seja, profissões em que o seu exercício pressupõe uma formação de nível superior. Uma característica fundamental dessas profissões é a existência de um corpo de conhecimentos acadêmico-científicos em que se baseiam suas propostas, programas e procedimentos de intervenção profissional. É bem sabido que a inexistência do suporte desse corpo de conhecimentos coloca em cheque não apenas a legitimidade, mas também a própria existência e sobrevivência dessas profissões $(9,10,13)$. Mas, que corpo de conhecimentos?

É importante salientar que apesar de existirem diferentes tipos de conhecimentos úteis à prática profissional - como aqueles de natureza pessoal - assumese que a legitimidade social e profissional de uma profissão passam necessariamente pela legitimidade do corpo de conhecimentos em que ela se apóia. Daí concluir-se que os conhecimentos acadêmico-científicos são aqueles que devem constituir a base estrutural do corpo de conhecimentos que dá sustentação a uma profissão academicamente orientada. $\mathrm{O}$ mesmo não pode ser dito, evidentemente, em relação às profissões tecnicamente orientadas. A legitimidade acadêmico-científica do corpo de conhecimentos, por sua vez, pressupõe uma estrutura que organize a produção e a sistematização de conhecimentos, que seja capaz de projetar uma iden- 
tidade à área específica de conhecimento a que pertence. A essa estrutura dá se o nome de base epistemológica e ao conjunto de conceitos compartilhados que viabiliza a comunicação interna, o nome de estatuto epistemológico. Portanto, a definição de identidade acadêmica e sua consolidação mediante pesquisas acadêmico-científicas abrangentes e profundas podem ser entendidas como uma necessidade imperativa para a Educação Física e o Desporto $(9,10)$.

Para muitos pesquisadores, as necessidades da profissão devem orientar a natureza e conteúdo da atividade acadêmica de uma área, ou seja, as necessidades correntes e futuras da profissão devem ditar os tipos de perguntas a serem formulados pelos pesquisadores associados à área. Dentro dessa linha de raciocínio, a busca do conhecimento pelo conhecimento deve acontecer nas áreas comumente denominadas de puras ou básicas, em que não se tem preocupações com a sua aplicação prática por não haver nenhuma vinculação a um campo profissional específico.

No entanto, excetuando-se as abordagens filosóficas sobre a função, o significado e os objetivos da Educação Física e Desporto, além das tradicionais pesquisas relativas à análise do ensino e do comportamento de professores e administradores, em sua maioria caracterizada como pesquisas descritivas da situação, o quadro atual mostra que ainda não foram desenvolvidas linhas de pesquisa em número suficiente e produtivas, objetivando uma investigação sistemática de temas profissionalizantes relevantes para que os seus resultados pudessem ser colocados à disposição da preparação e intervenção profissionais. Pesquisadores envolvidos com o estudo de aspectos profissionalizantes continuam produzindo ensaios e artigos de tomada de posição, e tem faltado um esforço mais sistemático no sentido de se conduzir estudos empíricos para buscar evidências que suportem as idéias e pensamentos apresentados, problema já apontado há alguns anos $(9,10)$.

Temos aqui um problema de base epistemológica que necessita ser urgentemente equacionado pelas áreas. É preciso que os pesquisadores das subáreas de investigação atualmente existentes lancem mão da sua tendência integrativa como hólons intelectuais para se articularem com o objetivo de definir uma área comum com base epistemológica definida. Isto logrado, o próximo passo seria encontrar a gran- de área mais apropriada na qual pertencer. Pessoalmente entendo que a Educação Física e o Desporto ficariam adequadamente acomodados naquela que no cenário internacional mais amplo se denomina de ciências da vida (Life Sciences). Todavia, enquanto essa indefinição prevalece, a Educação Física e Desporto continuam a assistir a realização de pesquisas de todos os tipos - básicas, aplicadas e tecnológicas sem a necessária reflexão - fundamentalmente orientadas à busca do mérito acadêmicocientífico, mas muitas vezes com dificuldades de serem reconhecidas e enquadradas no que se refere a sua pertinência às especificidades das respectivas áreas. Como sobre esse assunto já me posicionei em trabalhos anteriores, aos interessados sugiro a leitura dos originais $(9,10,11,13)$.

Considerando as áreas de conhecimento da Educação Física e Desporto como hólons acadêmicos, outro aspecto que merece reflexão diz respeito à natureza da sua investigação. A ausência de uma estrutura que oriente os diferentes conteúdos e formas de investigação tem contribuído para disputas em torno de as pesquisas no seu interior serem realizadas numa concepção de ciências naturais ou humanas e sociais que têm resultado em divisões e cisões desnecessárias. E com frequência, isto tem sido acompanhado de uma boa dose de ideologização e politização das discussões. Como as subáreas de investigação que adotam concepções e metodologias das ciências naturais são identificadas como sendo alinhadas à corrente epistemológica positivista (por exemplo, Fisiologia do Exercício, Biomecânica, Comportamento Motor), são sistematicamente alvo de críticas daqueles que se identificam com correntes não-positivistas - a fenomenológica, a hermenêutica e mais especificamente a histórico-crítica. O inverso também é verdadeiro, sendo as subáreas sócio-culturais que adotam concepções e metodologias das ciências humanas e sociais (por exemplo, Antropologia do Desporto, Sociologia do Desporto, História do Desporto) alvo de críticas de que suas pesquisas não passam de discursos e opiniões desprovidos de qualquer verificação, ou ainda de que não têm sido capazes de ir além das discussões filosóficas genéricas para apresentar perspectivas concretas de pesquisa que enfoquem o fenômeno em si mediante linhas de pesquisa devidamente delineadas $(9,10)$. 
Evidentemente, essa disputa não é nada produtiva, mesmo porque o cerne da questão está na qualidade das pesquisas e publicações feitas, respeitadas as peculiaridades metodológicas e epistemológicas de cada subárea. A manutenção desse embate, por motivos outros que não sejam a busca do rigor no empreendimento acadêmico-científico certamente não contribuirá para o avanço das áreas.

Mas, independente dessa disputa, o que de concreto se observa na Educação Física e Desporto é o fato de a produção de conhecimentos profissionais de aplicação prática estar sendo colocada num segundo plano. As pesquisas básicas dominam o cenário, com o mérito, reconhece-se, de encontrar espaços para a sua publicação até em periódicos de áreas correlatas, muitas pertinentes às chamadas ciências mãe, de alta reputação e impacto. No entanto, é mais do que evidente a necessidade de fortalecer as pesquisas aplicadas, profissionalizantes, vinculadas à intervenção, buscando nos conhecimentos dessa natureza também a sua inserção internacional, ou seja, publicando-as em periódicos de reconhecida reputação e impacto. Não se confunde, portanto, com o pensamento muito comum na nossa área de que conhecimentos aplicados são publicados em periódicos locais, regionais ou nacionais, de menor exigência e baixo impacto. Sabidamente, conhecimentos que passam por um crivo rigoroso são mais confiáveis, inclusive na sua aplicação a problemas locais, regionais e nacionais. A garantia é a qualidade e não a naturalidade ou a nacionalidade do conhecimento.

A comunidade científica entende que a inserção internacional é o melhor indicador de qualidade. Em outras palavras, o trabalho que se submete à crítica de uma comunidade mais ampla tem maiores probabilidades de possuir melhor qualidade do que aquele que se submete à avaliação de uma comunidade mais restrita, por exemplo, local ou regional. Um artigo publicado em um periódico de reconhecimento internacional é entendido como um trabalho que tem inserção internacional(12).

Parte da comunidade de pesquisadores prognostica que a ênfase à publicação em periódicos internacionais resultará no empobrecimento e até no desaparecimento de periódicos nacionais. A carreira acadêmica envolve um processo de qualificação crescente em que o pesquisador vai gradativamente adquirindo competência científica, avalizada pelo reconhecimento da sua produção pelos pares. Por esse motivo, é altamente plausível, numa comunidade de pesquisadores, uma distribuição normal dos periódicos em que seus artigos são publicados, desde os locais aos internacionais. Fazer com que a média dessa comunidade se mova para a direita da curva, quando os periódicos são colocados em ordem crescente de qualidade, deve constituir-se uma meta de qualquer área. A Educação Física e o Desporto não podem ser diferentes ${ }^{(12)}$.

Ademais, todos reconhecem que, no âmbito internacional, a competitividade para publicar em periódicos mais qualificados aumenta sem parar, da mesma forma que cresce o número de pesquisadores qualificados. Portanto, é também plausível ter periódicos lusófonos publicando artigos cada vez mais qualificados que, como consequência, poderão obter a indexação internacional, como já ocorre, com alguns de seus periódicos. Os periódicos lusófonos devem buscar a indexação internacional e não permanecerem subscritos aos indexadores do seu nicho geográfico. O reconhecimento acadêmico-científico da comunidade lusófona de Educação Física e Desporto deve ser também holonômico: internamente pela vinculação cultural da sua produção intelectual e externamente pela inserção internacional dessa produção. Outra crítica freqüente é que a busca pela internacionalização da sua produção científica pode levar a Educação Física e o Desporto a abandonarem temas de investigação de interesse local ou regional. Um equívoco. Nada impede o pesquisador de diversificar as suas linhas de pesquisa para contemplar investigações de interesses mais específicos. E, para cada tema investigado, deve procurar um veículo de publicação mais adequado. Investigar tema de interesse local não significa que o estudo deva ser avaliado apenas localmente. $\mathrm{O}$ fato de o tema ser de interesse local ou regional não garante, obviamente, a qualidade do estudo realizado. Portanto, seria altamente salutar uma pesquisa em torno de um tema de interesse local ser avaliada, por exemplo, com o mesmo rigor que se aplica à análise de um artigo nacional ou internacional. De fato, se o método de investigação for único e original, apesar de o tema ser local, poderá atrair também o interesse de periódicos inclusive internacionais ${ }^{(12)}$. 
A vinculação do estudo a temas locais e a sua conseqüente publicação em periódicos domésticos pode ter um apelo meritório que é a pertinência do estudo a interesses específicos e concretos, mas o demérito de não expor o trabalho a crítica e avaliação mais amplas. Quando se submete um artigo a um periódico internacional, ele tem a possibilidade de ser avaliado por pesquisadores de diferentes países, apesar de o periódico ser publicado em um país específico. Evidentemente, um artigo necessita ser analisado e avaliado tanto na óptica do seu valor teórico-científico como da sua significância social. No entanto, não podemos deixar de ter sempre em mente que artigos sem qualidade não têm significado social. Poderá, ao contrário, ter um significado anti-social, especialmente se recebeu recursos financeiros públicos para a sua produção, sejam em forma de bolsas, auxílios ou equipamentos(12).

As divergências em torno da caracterização e pertinência da produção científica numa determinada área de conhecimento precisam levar em consideração a natureza da própria área, o que reforça a necessidade de uma melhor definição da base epistemológica da Educação Física e Desporto. Enquanto não se definem como uma área de natureza acadêmica ou profissionalizante, os simpatizantes de uma ou de outra concepção continuarão a defender um tipo de produção mais adequado à sua escolha.

Do ponto de vista dos periódicos, sugere-se que a comunidade lusófona pense na possibilidade de publicar três tipos de periódicos: os centrados em artigos originais de pesquisa (possuem dados empíricos) de natureza acadêmica e profissionalizante (a exemplo do Research Quarterly), os que veiculam artigos direcionados à disseminação de conhecimentos, pontos de vista, orientações e experiências úteis à intervenção profissional (a exemplo do Journal of Physical Education, Recreation and Dance - Joperd) e aqueles direcionados para a divulgação de ensaios temáticos de posicionamento e de reflexão (a exemplo da Quest).

Essas considerações em relação à publicação de artigos em periódicos não devem, em nenhuma hipótese, serem confundidas com pouca valorização da produção acadêmico-científica em forma de livros e capítulos de livro. Os conhecimentos produzidos pelas pesquisas realizadas nas subáreas ditas humanas e sociais da Educação Física e Desporto consti- tuem uma parte fundamental do seu acervo acadêmico-científico que deve ser ampliado e enriquecido. No entanto, cabe uma reflexão: nessas subáreas a produção de conhecimentos está muito concentrada em ensaios e capítulos de livro e, proporcionalmente, poucos artigos originais são produzidos. Até alguns anos atrás, esse quadro se justificava, em parte, pela ausência de periódicos específicos da área em número, qualidade, periodicidade e com regularidade garantida, mas hoje isso não mais corresponde à realidade. É necessário estimular mais a publicação de artigos originais, pois esses são os melhores indicadores de que existem linhas de pesquisa consolidadas e produtivas. O suposto número reduzido de opções de periódicos para quem investiga na área de humanas e sociais, tão propalado no nosso meio, não mais corresponde à realidade(12).

\section{A PÓS-GRADUAÇÃO COMO HÓLON}

Considerando o sistema de Pós-graduação como um hólon, observa-se a tendência auto-afirmativa dos programas refletir-se de forma cada vez mais forte na formação de mestres e doutores com uma visão estreita de ciência e de vida acadêmica e universitária, orientada apenas às dimensões microscópicas do seu objeto específico de investigação e a publicação de seus resultados em periódicos especializados. $\mathrm{Na}$ ânsia de concluir os seus cursos nos prazos estipulados e produzir artigos, ou mesmo para atender a exigências da competitividade instalada para obtenção de bolsas, o pós-graduando parece não mais entender como prioridade reservar um tempo na sua agenda para uma reflexão e aprendizagem sobre essas questões macroscópicas.

Reconhece-se que, muitas vezes, as exigências de dedicação num curso de doutorado não permitem maior aprofundamento em temas mais amplos que fogem às preocupações específicas do projeto de tese ${ }^{(11)}$. Entretanto, considerando que as atividades desenvolvidas após a conclusão do doutorado incluem, invariavelmente, a orientação de alunos de Pós-Graduação, a formação de grupos de estudo, a estruturação de laboratórios de pesquisa e outras atividades que requerem um conhecimento mais abrangente não apenas da área, mas da própria ciência, torna-se fundamental sensibilizar e estimular os pósgraduandos a adquirirem uma visão sistêmica de 
todo o processo. Nesse particular, entende-se que falta à Pós-graduação em Educação Física e Desporto promover uma formação mais sólida em História e Filosofia da Ciência, para que os pós-graduandos possam aprender a exercitar as duas faces do Janus. Em outras palavras, é preciso fazer a sua tendência integrativa se manifestar com mais vigor no sentido de utilizar sua capacidade de adaptação e criatividade na formação de mestres e doutores com uma visão sistêmica que lhes permita se posicionar acerca das dimensões macroscópicas da área de conhecimento, da universidade e da ciência(11). Os programas em funcionamento têm uma grande responsabilidade acadêmico-científica e social na formação de doutores devidamente capacitados para exercerem liderança científica na esfera de sua atuação. Deles depende, em grande parte, o futuro da Educação Física e Desporto dos países lusófonos.

Outro aspecto da Pós-graduação que merece uma reflexão profunda refere-se à distribuição dos programas na comunidade lusófona. Os programas de PósGraduação em funcionamento estão implantados em sua maioria em Portugal e no Brasil. Diluir essa concentração é um grande desafio, mas o processo é complexo em razão da necessidade de um corpo docente qualificado em nível de doutorado. Como se tem poucos doutores, não se criam novos programas de Pós-Graduação. E, em não se criando, não se formam os recursos humanos necessários para se implantar novos programas. Certamente, não existem soluções simples para se quebrar esse círculo vicioso. Exige-se muita ousadia e, especialmente, otimização de recursos humanos. Evidentemente, isso requer, em nível individual, uma disponibilidade para lutar por um projeto coletivo e, em nível institucional, um espírito cooperativo realçando em ambos a tendência integrativa do hólon. O programa de Pós-graduação da Universidade Pedagógica de Maputo, em parceria com a Faculdade de Desporto da Universidade do Porto e a Escola de Educação Física e Esporte da Universidade de São Paulo pode ser visto como uma evidência de que isso é possível.

\section{CONSIDERAÇÕES FINAIS}

Como foi visto, a definição de uma identidade acadêmica que oriente e organize a produção de conhecimentos em primeiro lugar, e, em segundo lugar, a consolidação da área mediante pesquisas científicas abrangentes e profundas devem ser entendidas não apenas como metas, mas como necessidades imperativas para a Educação Física e Desporto até mesmo para se justificarem como áreas de conhecimento merecedores de um lugar na academia e consequentemente na universidade.

A solução para esse problema implica uma ampla reflexão sobre a base epistemológica, o que se constitui um dos maiores desafios das nossas áreas.

Neste particular, um aspecto muito importante para a nossa consideração é que, apesar de, nos últimos anos, ter havido um aumento substancial no número de oportunidades para discussão e na quantidade de material escrito para leitura e reflexão, a preocupação com a identidade acadêmica da área ainda se restringe a um grupo muito reduzido de docentes e pesquisadores, dentre aqueles que atuam nas instituições de ensino superior.

Muitos continuam completamente afastados ou alienados da discussão, uns por puro desconhecimento (os chamados especialistas preocupados apenas com o seu campo específico de atuação e que dizem não ter tempo para discussões "paralelas"), outros por desinteresse para com qualquer coisa que seja acadêmica, por convicção ou limitação (os chamados práticos), outros ainda por insensibilidade ao problema por considerar essa discussão inútil e irrelevante, ou seja, uma especulação filosófica sem resultados práticos (os chamados pesquisadores ortodoxos que fazem uma brutal ruptura entre ciência e filosofia, relegando o segundo a um plano secundário). As implicações dessa omissão, alienação e desinteresse são imensas, particularmente o seu efeito multiplicador tanto na Graduação quanto na Pós-graduação, por formar um ciclo autorreprodutor que, se não rompido, retardará em muito o desenvolvimento da área(10).

Para finalizar, conclamo os docentes e pesquisadores lusófonos para nos envolvermos nesse desafio utilizando a nossa capacidade intelectual e criatividade que a tendência integrativa do hólon nos proporciona, sem deixar de pesquisar temas do nosso campo específico de investigação que a tendência auto-afirmativa já garante. Isto é, desenvolver as nossas atividades mantendo o equilíbrio dinâmico das duas faces do Janus. 


\section{CORRESPONDÊNCIA}

\section{Go Tani}

Escola de Educação Física e Esporte - USP

Av. Prof. Mello Morais, 65 - São Paulo - SP, CEP

05508-030 - Brazil

E-mail: gotani@usp.br

\section{REFERÊNCIAS BIBLIOGRÁFICAS}

1. Bento JO, Marques AT (1991). Uma língua, um espaço, uma comunidade de ciência do desporto. In J.O. Bento e A.T. Marques (Eds.), As ciências do desporto e a prática desportiva. Volume 1. Porto: Faculdade de Ciências do Desporto e de Educação Física, p.23-28.

2. von Bertalanffy L (1968). General systems theory. New York: George Braziller.

3. Gleick J (1987). Chaos: Making a new science. New York: Penguin Books.

4. Haken H (1977). Synergetics. Heidelberg: Springer - Verlag.

5. Jantsch E (1980). The self-organizing universe: Scientific and human implications of an emerging paradigm of evolution. Oxford: Pergamon Press.

6. Koestler A (1967). The ghost in the machine. London: Hutchinson.

7. Lewin R (1993). Complexity: Life on the edge of chaos. London: Phoenix.

8. Prigogine I, Stengers I (1984). Order out of chaos: man's new dialog with nature. New York: Bantam Books.

9. Tani G (1996). Cinesiologia, educação física e esporte: Ordem emanente do caos na estrutura acadêmica. Motus Corporis, v.3, n.2, p.9-49.

10. Tani G (1998). 20 anos de ciências do esporte: um transatlântico sem rumo? Revista Brasileira de Ciências do Esporte Número Especial Comemorativo dos 20 Anos de Fundação, p.19-31.

11. Tani G (2000). Os desafios da pós-graduação em educação física. Revista Brasileira de Ciências do Esporte, v. 22, n. 1, p.79-90.

12. Tani G (2007). Educação física: por uma política de publicação visando à qualidade dos periódicos. Revista Brasileira de Ciências do Esporte, 29, 1, 9-22.

13. Tani G (2008). Área de conhecimento e intervenção profissional. In U.C. Corrêa (Org.), Pesquisa em comportamento motor: A intervenção profissional em perspectiva. São Paulo: Escola de Educação Física e Esporte da Universidade de São Paulo, p.14-25.

14. Waldrop MM (1992). Complexity: The emerging science at the edge of order and chaos. London: Penguin Books.

15. Wiener N (1948). Cybernetics. New York: John Wiley \& Sons.

16. Yates EF (Ed.) (1987). Self-organizing systems: The emergence of order. New York: Plenum Press. 